\title{
Efficient Preparation of Carbamates by Rh-Catalysed Oxidative Carbonylation: Unveiling the Role of the Oxidant
}

\author{
Amaia Iturmendi, ${ }^{a}$ Manuel Iglesias, ${ }^{* a}$ Julen Munárriz, ${ }^{b}$ Victor Polo, ${ }^{b}$ Jesús J. Pérez-Torrente ${ }^{a}$ and Luis A. Oro* ${ }^{a, c}$
}

The synthesis of a broad variety of carbamates from amines, alcohols and carbon monoxide has been achieved by means of a Rh-catalysed oxidative carbonylation reaction that uses Oxone as stoichiometric oxidant. In-depth studies on the reaction mechanism shed light on the intimate role of Oxone in the catalytic cycle.

The importance of developing new routes that permit a more efficient and straightforward access to organic carbamates is well illustrated by the extensive application of these molecules as pharmaceuticals, agrochemicals or materials in the chemical industry. ${ }^{1}$ In addition, carbamates are commonly used as amine protecting groups and are, therefore, important intermediates or starting materials in modern synthetic chemistry. $^{2}$

Classic approaches to the synthesis of carbamates from amines and alcohols usually entail the use of phosgene or its derivatives. ${ }^{3}$ Other relevant stoichiometric methods use azides, ${ }^{4}$ isocyanates, ${ }^{5}$ and $\mathrm{CO}_{2}$ or carbonates. ${ }^{6}$ Several catalysed processes that employ $\mathrm{CO}_{2}$ as a $\mathrm{C} 1$ source, amines and alcohols have also been developed. ${ }^{7}$

The synthesis of carbamates by oxidative carbonylation of $\mathrm{N}-\mathrm{H}$ bonds from readily available amines and alcohols has been achieved by means of $\mathrm{Pd}^{8}$ and $\mathrm{Au}^{9}$ catalysts under high pressures of $\mathrm{CO}$, usually above 40 bar. Noteworthy exceptions that operate under milder conditions are the methods reported by Orito $^{10}$ and Guang. ${ }^{11}$ An alternative method for the synthesis of carbamates by carbonylation under low CO pressure requires the use of aromatic and aliphatic azides as starting materials. ${ }^{12}$

The excellent activity of $\mathrm{Rh}$ catalysts towards carbonylation reactions $^{13}$ prompted us to investigate the activity of commercially available rhodium complexes in the synthesis of carbamates from amines, alcohols and carbon monoxide under mild conditions. Moreover, in order to broaden the synthetic significance and scope of this reaction we assessed Oxone (Potassium peroxymonosulfate, $\mathrm{KHSO}_{5}$ ) as oxidant, which is an inexpensive, safe and environmentally friendly reagent. ${ }^{13 e}$

Initial catalytic tests aimed at evaluating the activity of various commercially available rhodium complexes in the oxidative carbonylation of aniline with 1-hexanol (5 equivalents). The reaction was completed after stirring at $100 \stackrel{\circ}{ } \mathrm{C}$ in toluene for $18 \mathrm{~h}$ under a carbon monoxide atmosphere (2 bar) using $[\mathrm{Rh}(\mu-$ $\mathrm{Cl})(\mathrm{COD})]_{2},[\mathrm{Rh}(\mu-\mathrm{MeO})(\mathrm{COD})]_{2}$ or $[\mathrm{Rh}(\mu-\mathrm{Cl})(\mathrm{Cl})(\mathrm{Cp} *)]_{2}(\mathrm{COD}=$ cyclooctadiene; $\mathrm{Cp}^{*}=$ pentamethylcyclopentadienyl) as catalysts and Oxone as oxidant ( 3 equivalents). The Rh(III) catalyst, $\left[\mathrm{Rh}(\mu-\mathrm{Cl})(\mathrm{Cl})\left(\mathrm{Cp}^{*}\right)\right]_{2}$, led to formation of carbamate/urea mixtures, while $[\mathrm{Rh}(\mu-\mathrm{Cl})(\mathrm{COD})]_{2}$ and $[\mathrm{Rh}(\mu-$ $\mathrm{MeO})(\mathrm{COD})]_{2}$ afforded exclusively the carbamate in identical isolated yields (75\%). Building on these results we decided to explore the scope of $[\mathrm{Rh}(\mu-\mathrm{Cl})(\mathrm{COD})]_{2}$ as a catalyst for this reaction using a variety of amines and alcohols.

Aniline can be efficiently converted into its corresponding carbamates employing a variety of primary and secondary alcohols without the formation of decarboxylation products or ureas (Scheme 1). The compatibility of this methodology with a variety of amines was also tested (Scheme 2 ).

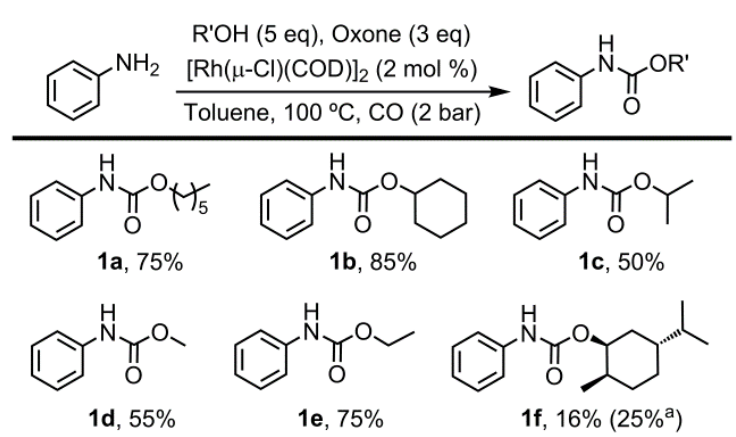

Scheme 1 Oxidative carbonylation of aniline with various alcohols (isolated yields after $16 \mathrm{~h}) .{ }^{\mathrm{a}}$ Isolated yield after $5 \mathrm{~d}$.

In view of the potential applicability of this methodology in the synthesis of bioactive molecules it is significant that the presence of carboxylic acids does not seem to thwart the reaction, in fact, $\mathbf{2} \mathbf{h}$ is obtained in excellent yields. In addition, compounds $\mathbf{2} \mathbf{i}$ and $\mathbf{2} \mathbf{j}$ were obtained from 2 -aminopyridine and cyclohexylamine, respectively, which demonstrates that the catalyst performs well even with potentially chelating substrates and with aliphatic amines.

In order to assess the scope of this methodology, a secondary alcohol, 2-propanol, was used instead of 1-hexanol (Scheme 3). Except for $\mathbf{3 c}, \mathbf{3 e}$ and $\mathbf{3} \mathbf{j}$ the expected carbamates were obtained successfully, although the use of a secondary alcohol seems to bring about somewhat lower yields in most cases, probably due to its increased steric hindrance. In fact, bulky amines such as ortho-substituted anilines or cyclohexylamine are particularly affected. Remarkably, this methodology permits the phosgene-free preparation of chlorpropham (3g), an example of carbamate-based marketed drug. ${ }^{3 a, 12}$

The use of imines as starting materials also yields directly the corresponding carbamates without the need for previous transformation into the related amines. Compounds $\mathbf{1 a}$ and $\mathbf{1 c}$ were obtained by reaction of imines $\mathbf{4}$ and $\mathbf{5}$ with 1-hexanol or 2-propanol (Scheme 4). A plausible explanation for this reaction would be that, in the presence of adventitious water, the imines deliver in situ the corresponding amines. 


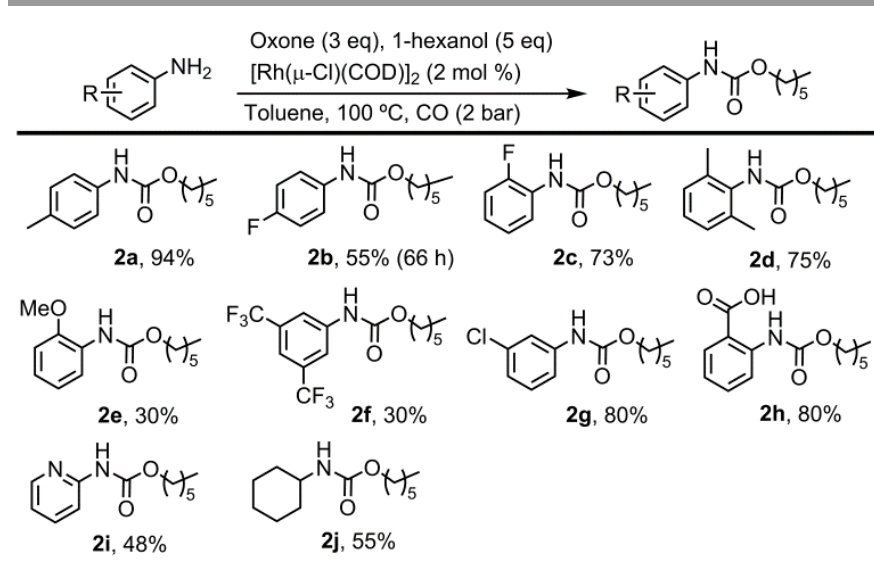

Scheme 2 Oxidative carbonylation of amines with 1-hexanol (isolated yields after $16 \mathrm{~h}$ ).

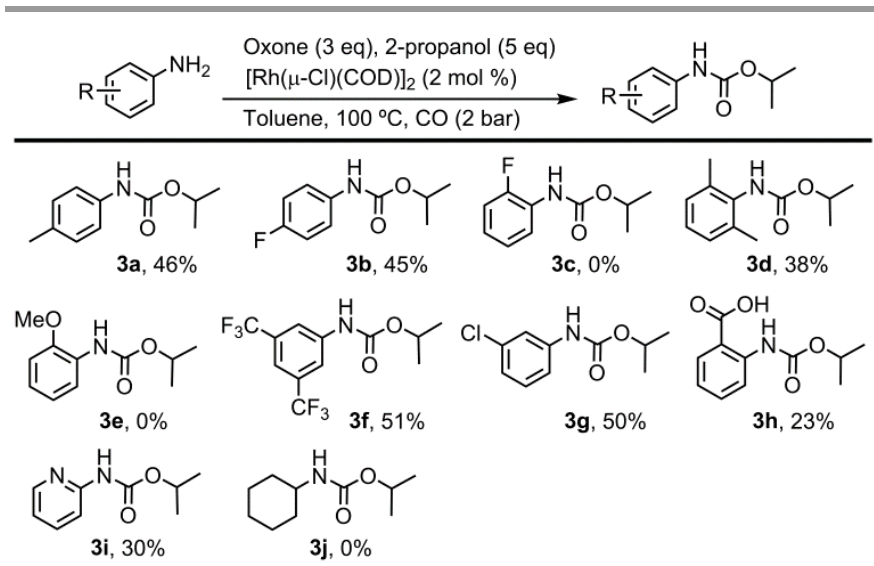

Scheme 3 Oxidative carbonylation of amines with 2-propanol (isolated yields after 16 h).

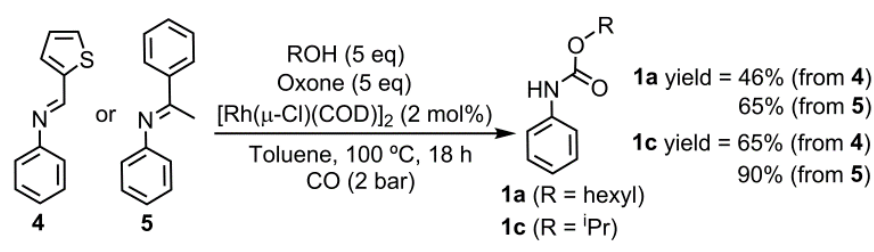

Scheme 4 Direct preparation of carbamates form imines (isolated yields).

Subsequently, the formation of the carbamate and concomitant generation of a $\mathrm{H}_{2} \mathrm{O}$ molecule and the consumption of free amine from the reaction mixture would drive the hydrolysis equilibrium toward the formation of more amine.

The mechanistic information on Rh-catalysed oxidativecoupling reactions is limited, and the role played by the oxidant is still a source of controversy. Moreover, the studies published so far have focused mainly on $\mathrm{Rh}$ (III) catalysts that make use of $\mathrm{Cu}(\mathrm{OAc})_{2}$ as stoichiometric oxidant. ${ }^{14,15}$ Recently, various examples of alkoxycarbonylation of $\mathrm{C}-\mathrm{H}$ bonds that use $\mathrm{Rh}(\mathrm{I})$ catalysts and persulfates as the oxidant have been reported. ${ }^{16}$ Two different mechanisms have been postulated for this type of reactions. ${ }^{17}$ The first, proposed by Zhang et al. for the directed alkoxycarbonylation of arenes, entails the abstraction of a hydrido ligand, formed by previous oxidative addition of the substrate's $\mathrm{C}-\mathrm{H}$ bond, and the proton of a coordinated alcohol by Oxone (Scheme 5a). ${ }^{17 a}$ On the other hand, a report by $\mathrm{Li}$ and co-workers proposes the oxidation of $[\mathrm{Rh}(\mu-\mathrm{Cl})(\mathrm{COD})]_{2}$ to a $\mathrm{Rh}(\mathrm{III})$ species by $\mathrm{K}_{2} \mathrm{~S}_{2} \mathrm{O}_{8}$ as first step of the catalytic cycle for the non-directed alkoxycarbonylation of indenes (Scheme 5b). ${ }^{17 b}$

Prompted by the scarce mechanistic knowledge on this type of oxidations, we set off to study the role played by Oxone in the catalytic cycle and the intimate mechanism through which the complex or substrates interact with the oxidant.

An NMR study showed that a solution of 0.5 equivalents of $[\mathrm{Rh}(\mu-\mathrm{Cl})(\mathrm{COD})]_{2}, 1$ equivalent of aniline, 1-hexanol and Oxone afforded complex $\left[\mathrm{Rh}(\mathrm{Cl})(\mathrm{CO})_{2} \text { (aniline) }\right]^{18}$ under a $\mathrm{CO}$ atmosphere at room temperature in $\mathrm{CD}_{2} \mathrm{Cl}_{2}$. No further reaction was observed upon an increase of the temperature to $50{ }^{\circ} \mathrm{C}$. Attempts to detect $\mathrm{CO}$ insertion intermediates by reaction of $[\mathrm{Rh}(\mu-\mathrm{Cl})(\mathrm{COD})]_{2}$ with aniline or 1-hexanol under a $\mathrm{CO}$ atmosphere in toluene- $\mathrm{d}_{8}$ at $100{ }^{\circ} \mathrm{C}$ were unsuccessful. However, when Oxone, 1-hexanol, aniline and 0.5 equivalents of $[\mathrm{Rh}(\mu-\mathrm{Cl})(\mathrm{COD})]_{2}$ were reacted at $100{ }^{\circ} \mathrm{C}$ in toluene under a $\mathrm{CO}$ atmosphere, the carbamate and $\left[\mathrm{Rh}(\mathrm{Cl})(\mathrm{CO})_{2}\right.$ (aniline)] were obtained; conversely, at room temperature no carbamate formation was observed. This suggests that, in this case, Oxone acts before any metal-mediated substrate activation takes place.

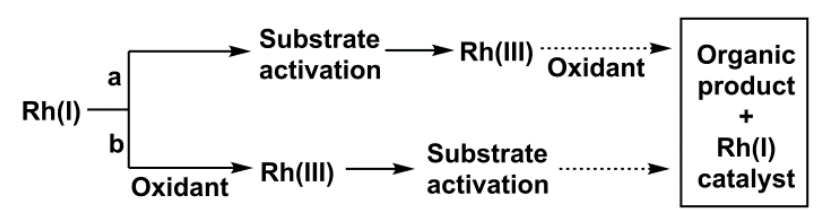

Scheme 5 Differences between the role played by the oxidant in the mechanisms proposed by Zhang and $\mathrm{Li}$. 


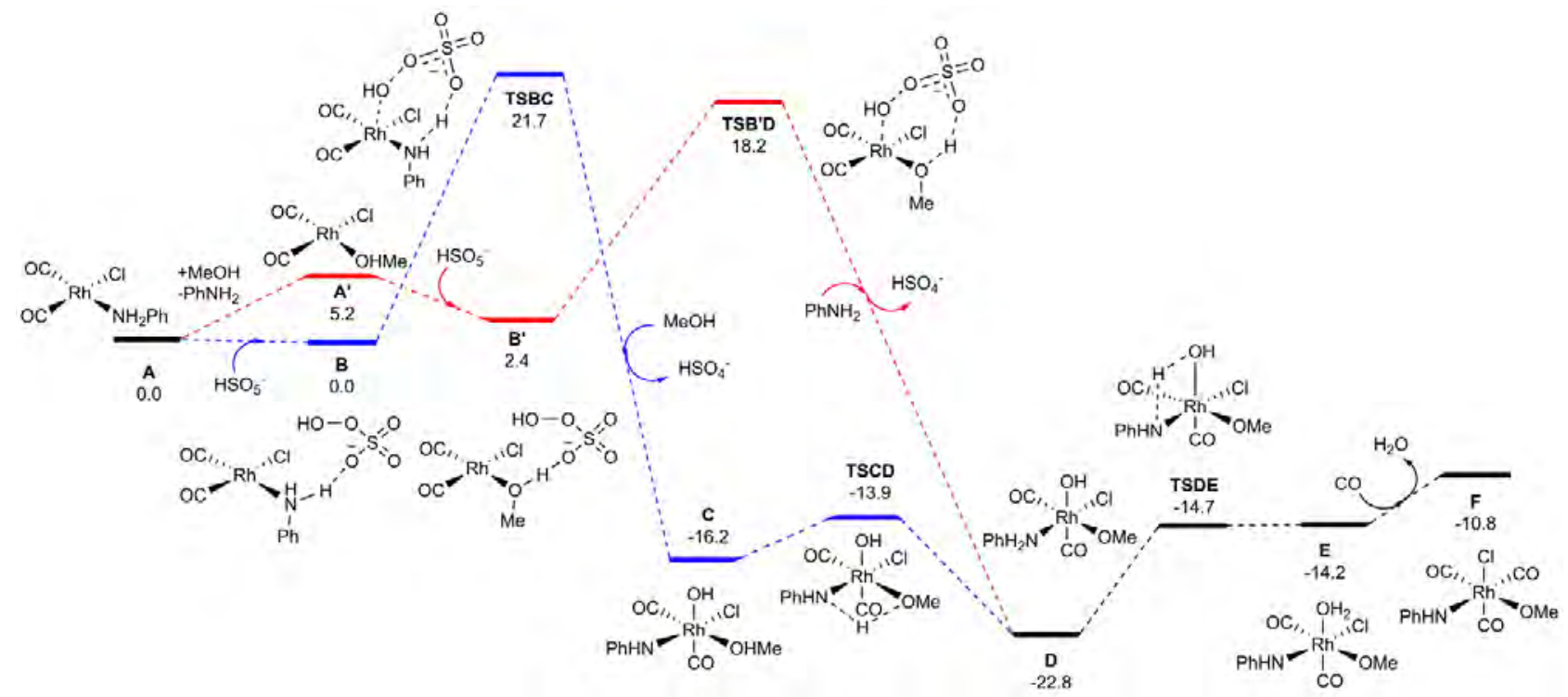

Fig. 1 DFT calculated Gibbs free energy profile (in $\mathrm{kcal} \cdot \mathrm{mol}^{-1}$ and relative to $\mathbf{A}$ and isolated molecules) for the Rh-catalysed oxidative carbonylation of amines.

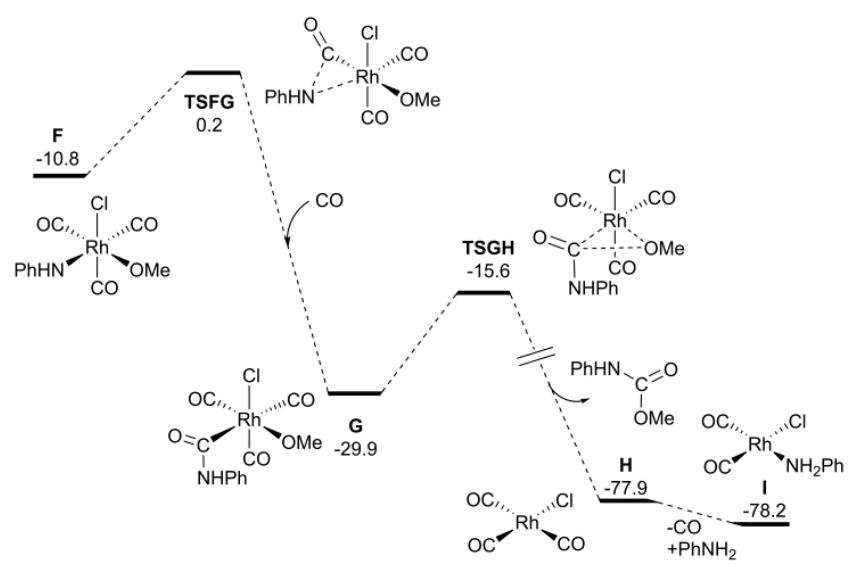

Fig. 2 DFT calculated Gibbs free energy profile (in $\mathrm{kcal} \cdot \mathrm{mol}^{-1}$ and relative to $\mathbf{A}$ and isolated molecules) for Rh-catalysed oxidative carbonylation of amines.

In order to shed light on the reaction mechanism, a computational study at the DFT level was performed using the B3LYP-D3 functional, considering $\left[\mathrm{Rh}(\mathrm{Cl})(\mathrm{CO})_{2}\right.$ (aniline)] as the catalyst (A) and $\mathrm{MeOH}$ as the alcohol. Fig. 1 shows the most plausible mechanism of action of Oxone according to the theoretical calculations and experimental data. Two related pathways can be postulated. In the first, Oxone interacts directly with $\left[\mathrm{Rh}(\mathrm{Cl})(\mathrm{CO})_{2}\right.$ (aniline)] (blue lines) while, in the second, previous substitution of aniline by $\mathrm{MeOH}$ is required (red lines). In both cases, the oxidation of the Rh centre and the deprotonation of the substrate (alcohol or aniline) take place according to a concerted mechanism at the beginning of the catalytic cycle, ${ }^{\ddagger}$ prior to substrate activation or migratory insertion..$^{\S}$ Under the reaction conditions both reaction pathways may occur simultaneously although the second path (red lines) features a slightly lower activation barrier. This mechanism entails that, after formation of $\mathbf{A}^{\prime}$, the coordinated methanol molecule interacts with Oxone by a hydrogen bond to give adduct $\mathbf{B}^{\prime}$. This triggers the oxidation of $\mathrm{Rh}(\mathrm{I})$ to $\mathrm{Rh}$ (III) by means of a concerted transition state (TSB'D) in which
Oxone deprotonates the methanol ligand and transfers the hydroxo group to the metal. Simultaneously, release of $\mathrm{HSO}_{4}^{-}$ and formation of $\mathbf{D}$ upon coordination of aniline take place. The presence of the $\mathrm{OH}$ ligand allows for the deprotonation of the coordinated amine, thus affording the aquo-complex $\mathbf{E}$ via TSDE, surmounting an energetic barrier of $8.1 \mathrm{kcalmol}^{-1}$. Carbonylation and isomerisation of $\mathbf{E}$ gives $\mathrm{Rh}(\mathrm{III})$-amido complex F. The downslope pathway thereafter (Fig. 2) entails the migratory insertion of the carbonyl ligand into the $\mathrm{M}-\mathrm{N}$ bond, thus forming intermediate G. Finally, reductive elimination of the carbamoyl ( $\mathrm{NHHC}(\mathrm{O})$-) and alkoxo (RO-) ligands, according to transition state TSGH, affords the corresponding carbamate and regenerates the catalyst (A) after exchange of the carbonyl ligand by aniline.

Noteworthy, the relatively low energy span calculated for the catalytic cycle $\left(23.0 \mathrm{kcal} \cdot \mathrm{mol}^{-1}\right)$ from intermediate $\mathbf{D}$ to the transition state TSFG does not seem to justify the high temperatures required for this reaction. This apparent inconsistency, however, is in accord with the almost negligible solubility of Oxone in organic solvents and the ensuing reactivity problems reported in the literature. ${ }^{19}$ Therefore, the reaction rate probably depends on the concentration of Oxone in the solution, which increases at higher temperatures. In this regard, we performed the synthesis of 1a (Scheme 1) in the presence of a phase transfer catalyst, namely $4 \mathrm{~mol} \%$ of tetrabutylammonium tetrafluoroborate, which acts as a surfactant that solubilises Oxone. In this case, the reaction takes place at 50 우; however, ca. $40 \%$ of aldehyde was obtained as a by-product due to alcohol oxidation.

In conclusion, we have disclosed a $\mathrm{Rh}(\mathrm{I})$-catalysed threecomponent reaction that allows for the preparation of carbamates from amines (or imines), alcohols and carbon monoxide under mild conditions, affording water and $\mathrm{KHSO}_{4}$ as the only reaction by-products. This process is catalysed by the commercially available complex $[\mathrm{Rh}(\mu-\mathrm{Cl})(\mathrm{COD})]_{2}$ in the presence of Oxone. This methodology shows a good tolerance to several functional groups and is compatible with primary 
and secondary alcohols. Theoretical and experimental data suggest that Oxone plays a dual role as base and oxidant, thus allowing for initial oxidation of the $\mathrm{Rh}$ (I) pre-catalyst to a $\mathrm{Rh}$ (III) species-this step being essential to achieve substrate activation. Remarkably, this transformation requires previous coordination of the alcohol because its deprotonation and the oxidation of the metal centre occur by a concerted mechanism.

\section{Acknowledgements}

This work was supported by the Spanish Ministry of Economy and Competitiveness (MINECO/FEDER) (CONSOLIDER INGENIO CSD2009-0050, CTQ2013-42532-P and CTQ2015-67366-P projects) and the DGA/FSE-E07. The support from KFUPMUniversity of Zaragoza research agreement and the Centre of Research Excellence in Petroleum Refining \& KFUPM is gratefully acknowledged. V. P. acknowledges the support of BIFI-ZCAM. J. M. thanks the support from the Ministry of Education Culture and Sports (FPU14/06003).

\section{Notes and references}

¥ The use of 3-chloroperoxybenzoic acid as oxidant with or without an external base $\left(\mathrm{K}_{2} \mathrm{SO}_{4}\right.$ or DMAP) fails to afford the corresponding carbamates, which suggests that oxidant and base act according to a concerted mechanism.

$\S$ Alternative mechanisms where substrate activation precedes $\mathrm{Rh}(\mathrm{I}) \rightarrow \mathrm{Rh}$ (III) oxidation by Oxone or $\mathrm{Rh}(\mathrm{I}) \rightarrow \mathrm{Rh}$ (III) oxidation by Oxone occurs without substrate coordination show higher activation energies (see ESI).

1 A. K. Ghosh and M. Brindisi, J. Med. Chem. 2015, 58, 2895-2940.

2 for examples see: a) O. Dangles, F. Guibd and G. Balavoine, J. Org. Chem. 1987, 52, 4984-4993; b) A. Merzouk, F. Guibé and A. Loffet Tetrahedron Lett. 1992, 33, 477-480; c) G. Hancock, I.J. Galpin, B.A. Morgan, 1982, 23, 249-252.

3 For examples see: a) T. A. Unger in Pesticides Synthesis Book, Ed. W. Andrew, Noyes Publications, New Jersey, 1996; b) H. Babad and A. G. Zeiler, Chem. Rev. 1973, 73, 75-91; c) S. M. Rahmathullah, J. E. Hall, B. C. Bender, D. R. McCurdy, R. R Tidwell and D. W. J. Boykin, Med. Chem. 1999, 42 3994-4000; d) N. A. Roberts, J. A. Martin, D. Kinchington, A. V. Broadhurst, J. C. Craig, I. B. Duncan, S. A. Galpin, B. K. Handa, J. Kay, A. Krohn, R. W. Lambert, J. H. Merrett, J. S. Mills, K. E. B. Parkes, S. Redshaw, A. J. Ritchie, D. L. Taylor, G. J. Thomas and P. J. Machin, Science 1990, 248, 358-361; e) H. Eckert and B. Forster, Angew. Chem., Int. Ed. Engl. 1987, 26, 894-895

4 E. F. V. Scriven and K. Turnbull, Chem. Rev. 1988, 88, 297-368.

5 G. Raspoet and M. T. Nguyen J. Org. Chem. 1998, 63, 68786885.

6 a) M. Yoshida, Na. Hara and S. Okuyama, Chem. Commun., 2000, 151-152; b) T. Tsuda, K. Watanabe, K. Miyata, H. Yamamoto and T. Inorg. Chem. 1981, 20, 2728-2730; c) A. Inesi, V. Mucciante and L. Rossi, J. Org. Chem. 1998, 63 1337-1338; d) W. D. McGhee, D. P. Riley, M. E. Christ and K. M. Christ, Organometallics 1993, 12, 1429-1433; e) R. N. Salvatore, J. A. Ledger and K. W. Jung, Tetrahedron Lett. 2001, 42, 6023-6025.
7 a) M. Abla, J. C. Choi and T. Sakakura, Chem. Commun. 2001 2238-2239; b) M. Abla, J. C. Choi and T. Sakakura, Green Chem. 2004, 6, 524-525; c) S. L. Peterson, S. M. Stucka and C. J. Dinsmore, Org. Lett. 2010, 12, 1340-1343; d) A. Julián, V. Polo, E. A. Jaseer, F. J. Fernández-Alvarez and L. A. Oro, ChemCatChem 2015, 7, 3895-3902 (preparation of silyl carbamates).

8 a) B. Gabriele, G. Salerno, R. Mancuso and M. Costa, J. Org. Chem. 2004, 69, 4741-4750; b) F. Shi, Y. Deng, T. SiMa and H. Yang, J. Catal. 2001, 203, 525-528; c) A. K. Ghosh and M. Brindisi, J. Med. Chem. 2015, 58, 2895-2940; d) S. Fukuoka, M. Chono and M. Kohno, J. Org. Chem. 1984, 49, 1458-1460; e) H. Alper and F. W. Hartstock, J. Chem. Soc., Chem. Commun., 1985, 1141-1142; f) S. Fukuoka, M. Chono and Masashi Kohno, J. Chem. Soc., Chem. Commun., 1984, 399400; g) B. Gabriele, R. Mancuso, G. Salerno and M. Costa, Top. Organomet. Chem. 2006, 18, 239-271.

9 F. Shi and Y. Deng, Chem. Commun., 2001, 443-444.

10 a) K. Orito, M. Miyazawa, T. Nakamura, A. Horibata, H. Ushito, H. Nagasaki, M. Yuguchi, S. Yamashita, T. Yamazaki, M. Tokuda, J. Org. Chem. 2006, 71, 5951-5958.

11 b) Z.-H. Guan, H. Lei, M. Chen, Z.-H. Ren, Y. Bai and Y.-Y. Wanga, Adv. Synth. Catal. 2012, 354, 489-496.

12 L. Rena and N. Jiao Chem. Commun., 2014, 50, 3706-3709.

13 a) J. P. Collman, L. S. Hegedus, J. R. Norton, R. G. Finke, Principles and Applications of Organotransition Metal Chemistry; University Science Books: Mill Valley, CA, 1978; b) Hartwig, J. F.; Organotransition metal chemistry-from bonding to catalysis. University Science Books. 2009, 753, 757-578; c) F. J. Fernández-Alvarez, M. Iglesias, L. A. Oro and V. Passarelli, in Comprehensive Inorganic Chemistry II, ed. J. Reedijk and K. Poeppelmeier, Vol 8. Oxford: Elsevier; 2013. p. 399-432; d) Z.-H. Guan, Z.-H. Ren, S. M Spinella, S. Yu, Y.-M. Liang and X. Zhang, J. Am. Chem. Soc. 2009, 131, 729-733; e) R. Lang, J. Wu, L. Shi, C. Xi and F. Li, Chem. Commun., 2011, 47, 12553-12555; B. Liu, F. Hu, and B.-F. Shi, ACSCatal. 2015, 5, 1863-1881; f) A. Iturmendi, P. J. Sanz Miguel, S. A. Popoola, A. A. Al-Saadi, M. Iglesias and L. A. Oro, Dalton Trans. 2016, 45, 16955-16965.

14 For computational studies see: a) I. Funes-Ardoiz and F. Maseras, Angew. Chem. Int. Ed. 2016, 55, 2764-2767; b) L. $\mathrm{Xu}, \mathrm{Q}$. Zhu, G. Huang, B. Cheng and Y. Xia, J. Org. Chem. 2012, 77, 3017-3024; c) N. Quiñones, A. Seoane, R. GarcíaFandiño, J. L. Mascareñas and M. Gulías, Chem. Sci. 2013, 4, 2874-2879; d) D. L. Davies, C. E. Ellul, S. A. Macgregor and C. L. McMullin, J. Am. Chem. Soc. 2015, 137, 9659-9669; d) J. Jiang, R. Ramozzi and K. Morokuma, Chem. Eur. J. 2015, 21, 11158-11164.

15 For experimental studies see: a) L. Li, W. W. Brennessel and W. D. Jones, Organometallics 2009, 28, 3492-3500; b) N. Wang, B. Li, H. Song, S. Xu and B. Wang, Chem. Eur. J. 2013, 19, 358-364.

16 B. Liu, F. Hu and B.-F. Shi, ACS Catal. 2015, 5, 1863-1881.

17 a) Z.-H. Guan, Z.-H. Ren, S. M. Spinella, S. Yu and Y.-M. Liang, Zhang, X. J. Am. Chem. Soc. 2009, 131, 729-733; b) R. Lang, J. L. Wu, L. J. Shi, C. G. Xia, and F. W. Li, Chem. Commun. 2011, 47, 12553-12555.

18 D. N. Lawson and G. Wilkinson, J. Chem. Soc. 1965, 19001907.

19 a) E. P. Bulman Page and B. R. Buckley in Mechanisms in Homogeneous and Heterogeneous Epoxidation Catalysis, Ed.: S. T. Oyama, Elsevier, Oxford, 2008, pp. 177-217; b) B. M. Trost, R. Braslau, J. Org. Chem., 1988, 53, 532-537. 